\title{
Carmustine Regimen
}

National Cancer Institute

\section{Source}

National Cancer Institute. Carmustine Regimen. NCI Thesaurus. Code C160007.

A chemotherapy regimen consisting of carmustine that may be used in the treatment of anaplastic gliomas and glioblastomas; adult low-grade infiltrative supratentorial astrocytoma/oligodendrog lioma (excluding pilocytic astrocytoma); and adult intracranial and spinal ependymomas (excluding subependymomas and myxopapillary ependymomas). 